\title{
Anesthetized Exsanguination and Perfusion Euthanasia
}

National Cancer Institute

\section{Source}

National Cancer Institute. Anesthetized Exsanguination and Perfusion Euthanasia. NCI Thesaurus. Code C106500.

A method of euthanasia whereby a subject is anesthetized and the blood of the body is replaced by a perfusate. 